Pacific Journal of Mathematics

A NOTE ON GLT GROUPS

FRY GILBERT BRAY 


\section{A NOTE ON CLT GROUPS}

\section{HENRY G. BRAY}

Let $A, B, C$ be respectively the class of all finite supersolvable groups, the class of all finite groups which satisfy the converse to Lagrange's theorem, and the class of all finite solvable groups. We show that $A \subset B \subset C$, and give examples to show that both of the inclusions are actually proper.

Throughout, ' $n$ ', ' $t$ ', ' $a_{1}$ ', ' $a_{2}$ ', $\cdots$, ' $a_{t}$ ' will denote positive integers; ' $p_{1}$ ', ' $p_{2}$ ', $\cdots$, ' $p_{t}$ ' will denote pairwise distinct positive integer primes. If $G$ and $H$ are finite groups, then, ' $G$ '" will denote the commutator subgroup of $G$, ' $G \times H$ ' will denote the external direct product of $G$ and $H$, and ' $|G|$ ' will denote the order of $G$. ' $A_{4}$ ' will denote the alternating group on 4 symbols, ' $e$ ' will denote the identity of $A_{4}$, and ' $C_{2}$ ' will denote the cyclic group of order 2 .

We are concerned here only with finite groups; throughout, when we say 'group', we intend this to be read as 'finite group', and ' $G$ ' will always denote a finite group. Our version of the converse to Lagrange's theorem is as follows:

Definition. $G$ is a CLT group if and only if for each $d$, the following holds: if $d$ is a positive integer divisor of $|G|$, then $G$ has at least one subgroup $H$ with $|H|=d$.

All terminology not used in the above definition will be that of [2].

Lemma 1. $|G|=n=p_{1}^{a_{1}} p_{2}^{a_{2}} \cdots p_{t}^{a_{t}}$ and $n_{i}=n / p_{i}^{a_{i}}$ for $i=1,2$, $\cdots, t$. Then $G$ is solvable if and only if $G$ has subgroups with orders $n_{1}, n_{2}, \cdots, n_{t}$.

Proof. This follows readily from Theorem 9.3.1, p. 141, and Theorem 9.3.3, p. 144 of [2].

Lemma 2. $|G|=n=p_{1}^{a_{1}} p_{2}^{a_{2}} \cdots p_{t}^{a_{t}}$ with $p_{1}<p_{2}<\cdots<p_{t}$. Then if $G$ is supersolvable, $G$ has normal subgroups with orders $1, p_{t}, p_{t}^{2}$, $\cdots, p_{t}^{a} t$.

Proof. This follows readily from Corollary 10.5.2, p. 159 of [2].

THEOREM 1. Every CLT group is solvable.

Proof. This is trivial if $|G|=1$. Let $G$ be a $C L T$ group with $|G|=n=p_{1}^{a_{1}} p_{2}^{\alpha_{2}} \cdots p_{t}^{a_{t}}$, and let $n_{i}=n / p_{i}^{a_{i}}$ for $i=1,2, \cdots, t$; since 
each $n_{i}$ is a divisor of $|G|, G$ must have subgroups with orders $n_{1}$, $n_{2}, \cdots, n_{t}$. Applying Lemma 1 , we conclude that $G$ is solvable, and this completes our proof.

The author wishes to thank Professor M. Hall for pointing out the proof of Theorem 1 .

\section{THEOREM 2. Every supersolvable group is CLT.}

Proof. This is trivial if $|G|=1$. We shall use induction on the number of positive integer primes dividing $|G|$ if $|G|>1$.

If $G$ is any group with $|G|=p_{1}^{a_{1}}$, then Sylow's theorem tells us that $G$ is $C L T$; in fact, any finite $p_{1}$-group is supersolvable, but we do not need this.

Suppose now that every supersolvable group whose order is divisible by exactly $t$ distinct positive integer primes is $C L T$, and let $G$ be a supersolvable group with $|G|=p_{1}^{a_{1}} p_{2}^{a_{2}} \cdots p_{t}^{a_{t}} p_{t+1}^{a_{t+1}}, p_{1}<p_{2}<\cdots$ $<p_{t}<p_{t+1}$. We shall show that $G$ is $C L T$, and our conclusion will follow. Let $d$ be a positive integer divisor of $|G|$; we wish to show that $G$ has a subgroup of order $d$. We may write $d=p_{1}^{b_{1}} p_{2}^{b_{2}} \ldots$ $p_{t}^{b_{t} t} p_{t+1}^{b_{t+1}}=r p_{t+1}^{b_{t+1}}$, where $b_{i}$ is an integer and $0 \leqq b_{i} \leqq a_{i}$ for each $i=1$, $2, \cdots, t, t+1$, and $r=p_{1}^{b_{1}} p_{2}^{b_{2}} \cdots p_{t}^{b_{t}}$. Since $G$ is supersolvable, $G$ is solvable, and we may apply Lemma 1 to conclude that $G$ has a subgroup $H$ with $|H|=n_{t+1}=p_{1}^{a_{1}} p_{2}^{a_{2}} \cdots p_{t}^{a_{t}}$. Now, $H$ is a subgroup of $G$, and $G$ is supersolvable; hence, $H$ is supersolvable and $|H|$ is divisible by exactly $t$ distinct positive integer primes. By our induction hypothesis, $H$ is $C L T$; since $r$ is a divisor of $n_{t+1}$ and $n_{t+1}=|H|$, it follows that $H$ must have a subgroup $R$ with $|R|=r$. Thus, $R$ is a subgroup of $G$ with $|R|=r$; since $G$ is supersolvable and $p_{t+1}$ is the largest prime dividing $|G|$, we may apply Lemma 2 to conclude that $G$ has a normal subgroup $P$ with $|P|=p_{t+1}^{b_{t+1}}$. Now let $R P$ be the set of all products $x y$ with $x \in R$ and $y \in P$; since $P$ is a normal subgroup of $G, R P$ is a subgroup of $G$. Also, $|R|$ and $|P|$ are relatively prime, so that $|R P|=|R| \cdot|P| /|R \cap P|=|R| \cdot|P|$; hence, $R P$ is a subgroup of $G$ with $|R P|=|R| \cdot|P|=r p_{t+1}^{b_{t+1}}=d$, and this completes our proof.

REMARK. Since every subgroup of a supersolvable group is supersolvable, it is clear that Theorem 2 can be used to prove the following: If $G$ is supersolvable, then every subgroup of $G$ is $C L T$. Sometime after the author had obtained Theorem 2, he became aware of the following (due to Professor W. Deskins): $G$ is supersolvable if and only if every subgroup of $G$ (including $G$ itself) is $C L T$. This appears in [1].

LemMA 3. Let $H$ be any group with $|H|=h$, where $h$ is odd. 
Then $\left|A_{4} \times H\right|=12 h$, and $A_{4} \times H$ has no subgroups of order $6 h$.

Proof. Suppose to the contrary that $A_{4} \times H$ has a subgroup $K$ with $|K|=6 h$; then $K$ has index 2 in $A_{4} \times H$, so that $K$ is a normal subgroup of $A_{4} \times H$ and $\left|\left(A_{4} \times H\right) / K\right|=2$. Hence, $\left(A_{4} \times H\right) / K$ is Abelian, so that $\left(A_{4} \times H\right)^{\prime}=A_{4}^{\prime} \times H^{\prime}$ is a subgroup of $K$; it follows that $\left|A_{4}^{\prime}\right|$ must divide $|K|$. Now $A_{4}^{\prime}=\{e,(12)(34),(13)(24),(14)(23)\}$, so that 4 must divide $|K|=6 h$; this is not possible, since $h$ is odd, and this completes our proof.

Lemma 4 . Let $H$ be any group of odd order; then $A_{4} \times H$ is solvable and not CLT.

Proof. According to Thompson and Feit, $H$ is solvable; since $A_{4}$ is solvable, it follows that $A_{4} \times H$ is solvable. The result of Lemma 3 shows that $A_{4} \times H$ is not $C L T$, and this completes our proof.

Lemma 5. Let $G$ be any CLT group; then $\left(A_{4} \times C_{2}\right) \times G$ is CLT and not supersolvable.

Proof. It is clear that a finite direct product of CLT groups is itself $C L T$, and it is clear that $A_{4} \times C_{2}$ is $C L T$; it follows that $\left(A_{4} \times C_{2}\right) \times G$ is $C L T$. Now Lemma 3 shows that $A_{4}$ is not $C L T$, and Theorem 2 then shows that $A_{4}$ is not supersolvable; it follows that $\left(A_{4} \times C_{2}\right) \times G$ is not supersolvable, and this completes our proof.

Our results show that the class of $C L T$ groups fits properly between the class of supersolvable groups and the class of solvable groups. As a closing remark, we note the following: If $G$ is supersolvable (solvable) then every subgroup of $G$ and every factor group of $G$ is supersolvable (solvable); that this is not true for $C L T$ groups in general is shown by the following example. Let $M$ be any $C L T$ group; then $\left(A_{4} \times C_{2}\right) \times M$ is $C L T$, but $\left(A_{4} \times C_{2}\right) \times M$ has $A_{4}$ as both a subgroup and a factor group, and $A_{4}$ is not $C L T$.

\section{REFERENCES}

1. W. E. Deskins, A characterization of finite supersolvable groups, Amer. Math. Monthly, 75 (1968), 180-182.

2. M. Hall, The Theory of Groups, The Macmillan Company, New York, New York, 1959.

Received November 6, 1967.

San Diego State College

SAN Diego, California 



\section{PACIFIC JOURNAL OF MATHEMATICS}

\section{EDITORS}

\section{H. ROYDEN}

Stanford University

Stanford, California

\author{
R. R. Phelps \\ University of Washington \\ Seattle, Washington 98105
}

\section{J. DugundJI}

Department of Mathematics University of Southern California Los Angeles, California 90007

\section{RICHARD ARENS}

University of California

Los Angeles, California 90024

\section{ASSOCIATE EDITORS}

\section{E. F. BECKENBACH}

B. H. NEUMANN

F. WOLF

K. YOSIDA

\section{SUPPORTING INSTITUTIONS}

UNIVERSITY OF BRITISH COLUMBIA CALIFORNIA INSTITUTE OF TECHNOLOGY UNIVERSITY OF CALIFORNIA MONTANA STATE UNIVERSITY UNIVERSITY OF NEVADA NEW MEXICO STATE UNIVERSITY OREGON STATE UNIVERSITY UNIVERSITY OF OREGON OSAKA UNIVERSITY UNIVERSITY OF SOUTHERN CALIFORNIA

\author{
STANFORD UNIVERSITY \\ UNIVERSITY OF TOKYO \\ UNIVERSITY OF UTAH \\ WASHINGTON STATE UNIVERSITY \\ UNIVERSITY OF WASHINGTON \\ AMERICAN MATHEMATICAL SOCIETY \\ CHEVRON RESEARCH CORPORATION \\ TRW SYSTEMS
}

NAVAL WEAPONS CENTER

Mathematical papers intended for publication in the Pacific Journal of Mathematics should be in typed form or offset-reproduced, double spaced with large margins. Underline Greek letters in red, German in green, and script in blue. The first paragraph or two must be capable of being used separately as a synopsis of the entire paper. It should not contain references to the bibliography. Manuscripts, in duplicate if possible, may be sent to any one of the four editors. All other communications to the editors should be addressed to the managing editor, Richard Arens, University of California, Los Angeles, California 90024.

Each author of each article receives 50 reprints free of charge; additional copies may be obtained at cost in multiples of 50 .

The Pacific Journal of Mathematics is published monthly. Effective with Volume 16 the price per volume (3 numbers) is $\$ 8.00$; single issues, $\$ 3.00$. Special price for current issues to individual faculty members of supporting institutions and to individual members of the American Mathematical Society: $\$ 4.00$ per volume; single issues $\$ 1.50$. Back numbers are available.

Subscriptions, orders for back numbers, and changes of address should be sent to Pacific Journal of Mathematics, 103 Highland Boulevard, Berkeley 8, California.

Printed at Kokusai Bunken Insatsusha (International Academic Printing Co., Ltd.), 7-17, Fujimi 2-chome, Chiyoda-ku, Tokyo, Japan.

PUBLISHED BY PACIFIC JOURNAL OF MATHEMATICS, A NON-PROFIT CORPORATION

The Supporting Institutions listed above contribute to the cost of publication of this Journal, but they are not owners of publishers and have no responsibility for its content or policies. 


\section{Pacific Journal of Mathematics}

\section{Vol. 27, No. $2 \quad$ February, 1968}

Leonard E. Baum and George Roger Sell, Growth transformations for

functions on manifolds ............................ 211

Henry Gilbert Bray, A note on CLT groups ................... 229

Paul Robert Chernoff, Richard Anthony Rasala and William Charles

Waterhouse, The Stone-Weierstrass theorem for valuable fields....... 233

Douglas Napier Clark, On matrices associated with generalized

interpolation problems ................................

Richard Brian Darst and Euline Irwin Green, On a Radon-Nikodym theorem for finitely additive set functions . ...................... 255

Carl Louis DeVito, A note on Eberlein's theorem..................... 261

P. H. Doyle, III and John Gilbert Hocking, Proving that wild cells exist . . . 265

Leslie C. Glaser, Uncountably many almost polyhedral wild $(k-2)$-cells in

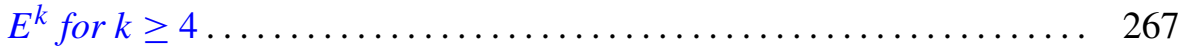

Samuel Irving Goldberg, Totally geodesic hypersurfaces of Kaehler

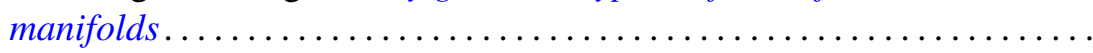

Donald Goldsmith, On the multiplicative properties of arithmetic functions .................................... 283

Jack D. Gray, Local analytic extensions of the resolvent ............ 305

Eugene Carlyle Johnsen, David Lewis Outcalt and Adil Mohamed Yaqub,

Commutativity theorems for nonassociative rings with a finite division ring homomorphic image ....................

André (Piotrowsky) De Korvin, Normal expectations in von Neumann

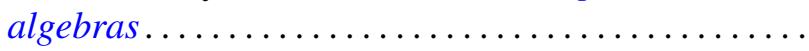

James Donald Kuelbs, A linear transformation theorem for analytic

Feynman integrals..........................

W. Kuich, Quasi-block-stochastic matrices ................... 353

Richard G. Levin, On commutative, nonpotent archimedean

semigroups ............................... 365

James R. McLaughlin, Functions represented by Rademacher series ... . . . 373

Calvin R. Putnam, Singular integrals and positive kernels............ 379

Harold G. Rutherford, II, Characterizing primes in some noncommutative

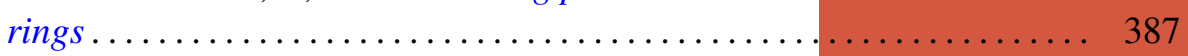

Benjamin L. Schwartz, On interchange graphs................... 393

Satish Shirali, On the Jordan structure of complex Banach *algebras . . . . . 397

Earl J. Taft, A counter-example to a fixed point conjecture............. 405

J. Roger Teller, On abelian pseudo lattice ordered groups ..... 